\title{
Tuberculosis and airflow obstruction: evidence from the PLATINO study in Latin America
}

\author{
A.M.B. Menezes*, P.C. Hallal*, R. Perez-Padilla\#, J.R.B. Jardim ${ }^{\star}$, A. Muiño ${ }^{+}$, \\ M.V. Lopez ${ }^{+}$, G. Valdivia ${ }^{\S}$, M. Montes de Oca ${ }^{\dagger}$, C. Talamo ${ }^{f}$, J. Pertuze ${ }^{\S}$ and \\ C.G. Victora* for the Latin American Project for the Investigation of Obstructive \\ Lung Disease (PLATINO) Team
}

ABSTRACT: The aim of the present study was to evaluate the association between history of tuberculosis and airflow obstruction.

A population-based, multicentre study was carried out and included 5,571 subjects aged $\geqslant 40$ yrs living in one of five Latin American metropolitan areas: Sao Paulo (Brazil); Montevideo (Uruguay); Mexico City (Mexico); Santiago (Chile); and Caracas (Venezuela). Subjects performed pre- and post-bronchodilator spirometry and were asked whether they had ever been diagnosed with tuberculosis by a physician.

The overall prevalence of airflow obstruction (forced expiratory volume in one second/forced vital capacity post-bronchodilator $<0.7$ ) was $30.7 \%$ among those with a history of tuberculosis, compared with $13.9 \%$ among those without a history. Males with a medical history of tuberculosis were 4.1 times more likely to present airflow obstruction than those without such a diagnosis. This remained unchanged after adjustment for confounding by age, sex, schooling, ethnicity, smoking, exposure to dust and smoke, respiratory morbidity in childhood and current morbidity. Among females, the unadjusted and adjusted odds ratios were 2.3 and 1.7, respectively.

In conclusion, history of tuberculosis is associated with airflow obstruction in Latin American middle-aged and older adults.

KEYWORDS: Chronic bronchitis, chronic obstructive pulmonary disease, developing countries, smoking, spirometry, tuberculosis

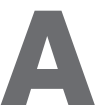
ccording to the global burden of disease projections [1], chronic obstructive pulmonary disease (COPD) and tuberculosis (TB) are among the 10 leading causes of death and disability for low- and middle-income countries at the beginning of the 21st century (sixth and eight, respectively). This scenario differs from that observed in high-income countries, where TB is not among the top 10 causes [1]. Brazil, the largest country in Latin America, is one of 22 countries in the world that accounts for $80 \%$ of the TB cases according to the World Heath Organization [2]. Poverty, malnutrition, high rates of HIV infection, smoking and the huge socioeconomic disparities observed in low- and middle-income countries contribute to the high prevalence of TB [2]

Previous studies have suggested that pulmonary TB is associated with airflow obstruction. Most were carried out in Africa [3-6] and Asia [7-9]. The Latin American literature on this issue is scarce; the current authors found only two papers, one from Chile and one from Brazil, published in the last 10 yrs [10,11]. Most studies had small samples and only one was population based. Post-bronchodilator spirometry, the gold standard for measuring airway obstruction, was used in several studies, but not in the populationbased survey [4].

The Latin American Project for the Investigation of Obstructive Lung Disease (PLATINO study) [12], a multicentre, population-based project conducted in five sites of Latin America, allowed the present authors to investigate the association between airflow obstruction (measured by spirometry) and TB (evaluated by medical diagnosis). The aim of the current study was to evaluate the association between airflow obstruction and TB.

\section{METHODS}

The PLATINO study was launched in 2002 [12]. The project focused on COPD and related
AFFILIATIONS

*Federal University of Pelotas,

Pelotas, and,

'Fedral University of Sao Paulo, Sao Paulo, Brazil.

\# National Institute of Respiratory Diseases, Mexico City, Mexico.

+University of the Republic, Montevideo, Uruguay.

${ }^{\S}$ Catholic University of Chile, Santiago, Chile.

${ }^{f}$ Central University of Venezuela Caracas, Venezuela.

CORRESPONDENCE

A.M.B. Menezes

Universidade Federal de Pelotas Rua Marechal Deodoro 1160 $3^{\circ}$ piso - 96020-220 - Pelotas Brazil

Fax: 555332841300

E-mail: anamene@terra.com.br

Received:

July 052007

Accepted after revision:

August 142007

\section{STATEMENT OF INTEREST}

Statements of interest for R. PerezPadilla and for the study itself can be found at www.erj.ersjournals.com/ misc/statements.shtml 
variables, including five major cities in Latin America: Sao Paulo (Brazil); Santiago (Chile); Mexico City (Mexico); Montevideo (Uruguay); and Caracas (Venezuela). The detailed methodology of the multicentre study was published elsewhere [13]. In brief, multistage sampling strategies were used to select subjects aged $\geqslant 40$ yrs in the five metropolitan areas, after stratification by administrative regions (main city and suburbs) and socioeconomic status of census tracts. An average of 15 households in 68 census tracts was visited per site. The sample was self-weighted in each city.

Interviews and examinations took place at the subjects' homes. Subjects performed pre- and post-bronchodilator (BD) spirometry using a portable, battery-operated, ultrasound transittime based spirometer (Easy-One IM); NDD Medical Technologies, Chelmsford MA, USA and Zurich, Swizerland). Approximately 90\% of all tests achieved "grade $\mathrm{A}^{\prime \prime}$ and almost 95\% fulfilled the American Thoracic Society (ATS) criteria of quality. Exclusion criteria for spirometry followed the ATS recommendations. Spirometric results were first presented as continuous variables: pre- and post-BD; forced expiratory volume in one second (FEV1); forced vital capacity (FVC); and FEV1/FVC. Two categorical variables were also created: airflow obstruction (yes or no) using a cutoff point of 0.7 in the post-BD FEV1/FVC ratio [14]; and the Global Initiative for Chronic Obstructive Lung Disease (GOLD) stages, using predicted values for normal lung function derived from the data from the present study [15]. GOLD categories II-IV were combined due to the small number of subjects in stages III and IV.

Information on medical diagnosis of TB was based on the question: "Has a doctor or other healthcare provider ever told you that you had tuberculosis?" For those who answered yes, the authors asked whether or not the subject used medication to treat the disease. Confounding variables included sex, age, ethnicity, schooling, smoking status, smoking history (packyrs), hospital admissions due to pulmonary problems in childhood, exposure to domestic biomass and coal pollution, occupational exposure to dust, body mass index and comorbidity (medical diagnosis of heart problems, hypertension, diabetes and stroke).

The combined sample size ( 5,600 individuals) allowed the current authors to detect significant odds ratios (ORs) of $\geqslant 1.8$ for the association between airflow obstruction (prevalence of $\sim 15 \%$ ) and medical diagnosis of TB (prevalence of $\sim 2.5 \%$ ) with power of $80 \%$ and confidence level of $95 \%$.

All analyses were stratified by study site. The analyses included a description of the sample, calculation of the prevalence of TB according to categories of the confounding variables, evaluation of mean spirometric results for subjects with and without a medical diagnosis of $\mathrm{TB}$, and logistic regression using the history of $\mathrm{TB}$ as the main exposure of interest. In the unadjusted analyses, Wald tests for heterogeneity or linear trend were applied, except when continuous variables were analysed; in this case, one-way ANOVA was used. Three logistic regression models for the association between medical diagnosis of TB and airflow obstruction were used. In the first, the crude association between the variables was studied. Secondly, the association was adjusted for sociodemographic variables, smoking, indoor and occupational exposure to pollution, and history of hospitalisation. In the last model, comorbidity indicators were also included. All analyses were repeated for males and females separately.

The study was approved by the Ethical Review Boards of the five institutions from the participating countries. Written informed consent was obtained from all participants, and confidentiality was ensured.

\section{RESULTS}

Detailed data on the sample included in the PLATINO study are available in previous publications [16]. In brief, 1,000 individuals aged $\geqslant 40$ yrs were interviewed in Sao Paulo, 1,208 in Santiago, 1,063 in Mexico City, 943 in Montevideo and 1,357 in Caracas. Nonresponse rates, including the spirometric evaluation, ranged from $31.1 \%$ in Mexico City to $16.3 \%$ in Sao Paulo. Nonrespondents were very similar to respondents in terms of cigarette smoking and age; the nonresponse rate was higher in males than females [16].

Out of 5,571 subjects, $132(2.4 \%)$ reported a medical diagnosis of TB. Of these, 105 reported the utilisation of medication to treat the disease. Table 1 describes the sample in terms of sociodemographic, behavioural, indoor and occupational exposure, and past and current morbidity. The male/female ratio was 0.65 , mean \pm SD age was $56.6 \pm 11.9$ yrs, the median duration of schooling was 6 yrs and more than half of the subjects $(3,012$ out of 5,553$)$ reported their skin colour as white. Prevalence of current smoking was $29.2 \%(1,625$ out of 5,569$)$ and $30.0 \%(1,660$ out of 5,536$)$ of all subjects were obese (body mass index $\left.\geqslant 30 \mathrm{~kg} \cdot \mathrm{m}^{-2}\right)$. History of hospitalisation due to respiratory problems in childhood was present for 2.2\% (121 out of 5,569$)$ of the subjects. Exposure to coal for cooking or heating was reported by $22.8 \%(1,269$ out of 5,563$)$ of the subjects, while exposure to biomass was positive for $44.4 \%$ $(2,467$ out of 5,559$)$. Half of the subjects $(2,840$ out of 5,564$)$ had never been exposed to dust at the workplace, while $27.8 \%$ $(1,548$ out of 5,564$)$ were exposed for $\geqslant 10$ yrs. In terms of comorbidity, $34.9 \%(1,943$ out of 5,570$)$ of the subjects reported suffering from hypertension, $13.6 \%$ (755 out of 5,570) from heart problems, $10 \%$ (554 out of 5,569) from diabetes and $2.4 \%$ (133 out of 5,568$)$ had a history of stroke.

Table 1 also presents the prevalence of medical diagnosis of TB according to the independent variables included in the survey. A positive association was detected between TB and age. TB was reported more often by subjects who were admitted to hospitals in childhood due to respiratory problems, those who were exposed to dust at the workplace, and those who were exposed to coal or biomass for cooking or heating. In terms of comorbidity, subjects with medical diagnoses of hypertension or stroke were more likely to report a medical diagnosis of TB.

In table 2, spirometric results are compared among subjects with and without a medical diagnosis of TB. For all spirometric indices, those with TB performed less well, although the relative difference tended to be greater for FEV1 than for FVC. When the spirometric values were converted into categorical outcomes, the association between TB and airflow obstruction was still significant and strong. Figure 1 shows the prevalence of medical diagnosis of TB according to the COPD stages of 


\section{TABLE 1 Prevalence of medical diagnosis of tuberculosis}

Variable

Sex

Male

Female

Age yrs

40-49

50-59

$\geqslant 60$

Highest degree of schooling

$0-2$

$3-4$

5-8

$\geqslant 9$

Ethnic origin

White

Mixed

Black

Indigenous

Asian

Smoking status

Never-smoker

Former smoker

Current smoker

Smoking exposure pack-yrs

0-9.9

$10-19.9$

$\geqslant 20$

Body mass index $\mathrm{kg} \cdot \mathrm{m}^{-2}$

$<25$

25-29.9

$\geqslant 30$

Hospital admission due to pulmonary problems in childhood

No

Yes

Indoor exposure to coal for cooking or heating

No

Yes

Indoor exposure to biomass for cooking or heating

No

Yes

Exposure to dust at the workplace

Never

$<10$

$\geqslant 10$

Medical diagnosis of hypertension

No

Yes

Medical diagnosis of diabetes

No

Yes

Medical diagnosis of heart problems

No

Yes
Sample $\mathbf{n}$

Medical diagnosis of tuberculosis

$\%$

p-value

0.11

2192

3379

1988

1625

1894

733

858

1882

2090

3012

1889

323

277

52

2400

1544

1625

3801

712

1030

1597

2279

1660

5448

121

4294

1269

3092

2467

2840

1176

1548

3627

1943

5015

554

4815

755
2.0

2.6

1.5

2.3

3.4

2.2

2.9

2.2

2.4

2.4

2.1

2.8

4.3

1.9

0.56

0.87

0.15

0.000

2.1

13.2

0.000

0.000

0.03

0.001

0.97

0.57

\#: Wald test for heterogeneity (dichotomous exposures and ethnicity) or linear trend (ordinal exposures). 


\section{TABLE 1 Continued.}

\begin{tabular}{lcc} 
Variable & Sample $\mathbf{n}$ & Medical diagnosis of tuberculosis \\
\cline { 2 - 3 } & & $\%$ \\
\hline Medical diagnosis of stroke & 5435 & 2.2 \\
No & 133 & 7.5 \\
Yes & & 0.000 \\
\hline \#: Wald test for heterogeneity (dichotomous exposures and ethnicity) or linear trend (ordinal exposures).
\end{tabular}

severity proposed by the GOLD classification. A history of TB was clearly associated with more severe grades of obstruction.

Table 3 presents the ORs for airflow obstruction (FEV1/FVC $<0.70$ ) according to reported TB. In the unadjusted analysis, the OR for obstruction was 4.06. Adjustment for different combinations of confounding variables did not change the crude results for males, with the adjusted OR being 3.99. For females, the magnitude of the association was lower than for males in the unadjusted analysis (OR 2.34); it was further reduced to 1.71 in the fully adjusted model $(p=0.08)$. For both sexes combined, those with TB presented an OR of 2.33 compared with those without TB in the fully adjusted model. Slightly stronger associations are obtained if airflow obstruction is defined as an FEV1/FVC lower than the fifth percentile for age, height and sex [15], that differ from the GOLD criteria, taking into account the decrease in FEV1/FVC with ageing (data available upon request).

\section{DISCUSSION}

In a population-based, multicentre study covering five large metropolitan areas in Latin America, a strong association was

\begin{tabular}{|c|c|c|c|}
\hline \multirow{3}{*}{ Spirometric values } & $\begin{array}{l}\text { ults accordi } \\
\text { berculosis }\end{array}$ & to med & \multirow{3}{*}{ p-value ${ }^{\#}$} \\
\hline & \multicolumn{2}{|c|}{$\begin{array}{l}\text { Medical diagnosis of } \\
\text { tuberculosis }\end{array}$} & \\
\hline & No & Yes & \\
\hline FEV1 pre-BD & $2.54 \pm 0.77$ & $2.17 \pm 0.71$ & 0.000 \\
\hline FEV1 pre-BD \% pred " & $95.69 \pm 18.32$ & $88.14 \pm 22.27$ & 0.000 \\
\hline FEV1 post-BD & $2.63 \pm 0.77$ & $2.26 \pm 0.70$ & 0.000 \\
\hline FEV1 post-BD \% pred & $95.82 \pm 17.14$ & $91.43 \pm 18.80$ & 0.007 \\
\hline FVC pre-BD & $3.37 \pm 0.97$ & $3.15 \pm 0.93$ & 0.009 \\
\hline FVC pre-BD \% pred & $98.69 \pm 16.96$ & $98.15 \pm 20.18$ & 0.72 \\
\hline FVC post-BD & $3.38 \pm 0.94$ & $3.12 \pm 0.88$ & 0.003 \\
\hline FVC post-BD \% pred & $98.12 \pm 15.52$ & $96.13 \pm 16.34$ & 0.16 \\
\hline FEV $1 / F V C$ pre-BD & $0.75 \pm 0.09$ & $0.69 \pm 0.11$ & 0.000 \\
\hline FEV $1 /$ FVC pre-BD \% pred & $97.72 \pm 10.76$ & $90.21 \pm 13.11$ & 0.000 \\
\hline FEV $1 / F V C$ post-BD & $0.78 \pm 0.08$ & $0.73 \pm 0.11$ & 0.000 \\
\hline FEV1/FVC post-BD \% pred & $97.85 \pm 10.00$ & $91.79 \pm 13.27$ & 0.000 \\
\hline
\end{tabular}

Data are presented as mean $\pm \mathrm{SD}$. FEV1: forced expiratory volume in one second; BD: bronchodilator; \% pred: \% predicted; FVC: forced vital capacity. \#: one way ANOVA; ${ }^{\circ}$ : predicted values were based on the PLATINO reference curves shown between a medical history of TB and airflow obstruction among subjects aged $\geqslant 40$ yrs. To the current authors' knowledge, this is the first population-based study exploring this association using post-BD spirometry. Previous studies on the subject included occupational cohorts with high prevalence of lung disease or addressed the natural history of $\mathrm{TB}$, including its effect on airflow obstruction, without an internal comparison group. It is well known that history of TB may affect lung function, either by pleural changes, bronchial stenosis or parenchymal scarring. Extensive lesions may produce restrictive changes with reduced transfer factor of the lung for carbon monoxide, but obstructive alterations were also identified many years ago $[17,18]$.

The association of TB with FEV1 values (mean difference $0.35 \mathrm{~mL})$ was stronger than for FVC $(0.25 \mathrm{~mL})$ and, as a result, the FEV1/FVC ratio showed a marked reduction, characterised by an obstructive pattern. Earlier studies that did not rely on post-BD spirometry suggested that $\mathrm{TB}$ can lead to chronic airflow obstruction [19-21], but subjects diagnosed with obstruction may be asthmatic, which is markedly less likely when a BD is used [14].

The current definition of COPD according to the GOLD criteria [14] takes into account history of smoking; therefore, the current authors opted to use the terminology "airflow obstruction" instead of COPD throughout the study. The present findings suggest that the limitation to airflow caused by $\mathrm{TB}$ is

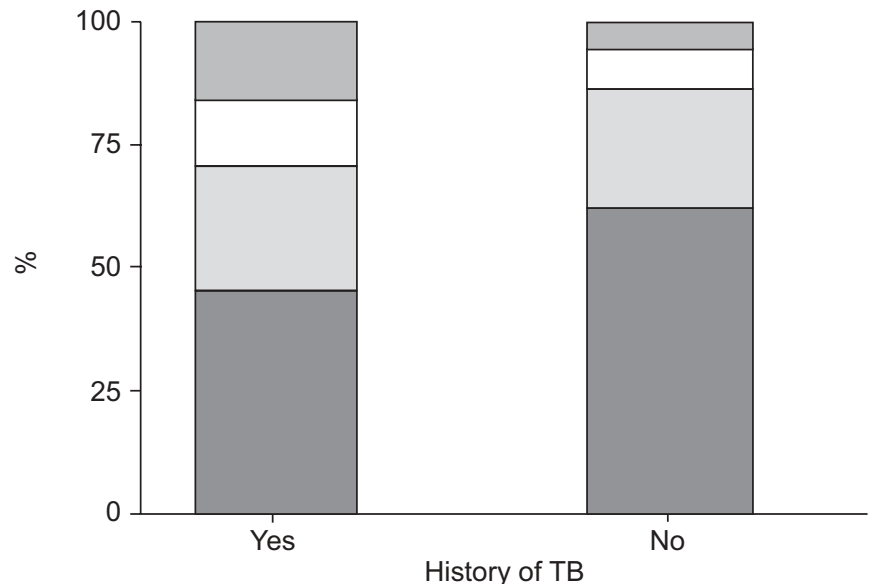

FIGURE 1. Prevalence of different stages of chronic obstructive pulmonary disease (COPD) severity according to medical history of tuberculosis (TB). $\square$ : no COPD; $\square$ : stage 0 ; $\square$ : stage I; 1 : stage II-IV 
TABLE 3 Unadjusted and adjusted odds ratios (OR) for airflow obstruction according to medical diagnosis of tuberculosis ${ }^{\#}$

\begin{tabular}{|c|c|c|c|c|c|c|}
\hline \multirow[t]{2}{*}{ Analysis } & \multicolumn{2}{|c|}{ Males } & \multicolumn{2}{|c|}{ Females } & \multicolumn{2}{|c|}{ Overall } \\
\hline & OR (95\% Cl) & p-value & OR (95\% Cl) & p-value & OR (95\% Cl) & $\mathrm{p}$-value \\
\hline Unadjusted & $4.06(2.13-7.71)$ & 0.000 & $2.34(1.39-3.92)$ & 0.001 & $2.75(1.88-4.03)$ & 0.000 \\
\hline Adjusted for level 1 & $4.49(2.27-8.87)$ & 0.000 & $1.87(1.04-3.35)$ & 0.04 & $2.57(1.69-3.93)$ & 0.000 \\
\hline Adjusted for levels 1 and 2 & $3.99(1.92-8.30)$ & 0.000 & $1.71(0.95-3.09)$ & 0.08 & $2.33(1.50-3.62)$ & 0.000 \\
\hline
\end{tabular}

independent from smoking, which is in accordance with previous studies. HNIZDO et al. [5] expanded this finding by showing that lung damage is directly associated with the number of episodes of TB among patients suffering from silicosis. Possible mechanisms include bronchial stenosis and lung scarring, and, in addition, similarly to exposure to smoke, TB increases the activity of the matrix metalloproteinases enzymes, thus contributing to pulmonary damage [22]. Tobacco smoking and biomass smoke inhalation, in addition to increasing the risk of $\mathrm{TB}$, may compound the airflow obstruction caused by TB [23-26]. In fact, a review recently suggested that subjects smoking $\geqslant 20$ cigarettes $\cdot$ day $^{-1}$ are two to four times more likely to present with TB than nonsmokers [27].

The present findings are relevant for public health. The projections from the global burden of disease ranked COPD as sixth in terms of mortality in low- and middle-income countries in 2001. TB appeared in eighth position immediately after HIV infection, which is strongly associated with TB and was ranked fourth. The reduction of TB is part of the sixth Millennium Development Goals [28]. The current findings suggest that by controlling $\mathrm{TB}$, the prevalence of airflow obstruction may also be reduced.

Some limitations of the study should be considered. First, medical diagnosis of TB may not reflect the actual incidence of the disease, because it may be affected by access to diagnostic and therapeutic facilities. The present analyses were repeated after excluding all subjects with less than primary education, and results were unchanged; the overall unadjusted OR, which was 2.75 in the whole sample, was 2.61 among those with at least secondary education. Adjustment for schooling did not substantially affect the association between TB and airflow obstruction. Recall bias may also affect the results; subjects who suffer from chronic respiratory conditions may be more likely to recall previous TB episodes than those who did not have any sequelae. The current authors believe that subjects who received treatment for $\mathrm{TB}$ are unlikely to under report, given the long duration and complexity of treatment, particularly in the past. The analyses was repeated excluding subjects who were not treated $(n=21)$, and the unadjusted OR was slightly increased (3.14 versus 2.75 in the original analyses). Another limitation is the fact that the medical diagnosis of TB was not confirmed by records or image exams due to logistic and financial limitations. Although this was a cross-sectional study, reverse causality was unlikely. Peak incidence of TB occurs in young adults whereas COPD peaks much later, and the survey was restricted to subjects aged $\geqslant 40$ yrs. Prospective studies are needed on this topic.

Relative to previous studies on this issue, it is important to highlight that the present study relied on probability samples of defined urban areas. Nonresponse rates were lower than in most population-based studies including a physical examination, such as spirometry [13]. The measurements of lung function followed strict rules and standardisation [13], and the fieldwork teams in each country were trained by the same supervisors, improving comparability in data collection.

The current authors found an important contribution of tuberculosis to airflow obstruction, linking two of the most common ailments in the world. The present results suggest that the prevention and adequate treatment of tuberculosis would reduce the burden of airflow obstruction in developing countries.

\section{ACKNOWLEDGEMENTS}

The members of the PLATINO study are as follows. M.N. Márquez (Faculty of Medicine, University of Republica, Montevideo, Uruguay); D. Moreno (Central University of Venezuela, Caracas); B. Celli (Caritas St Elizabeth's Medical Center, Boston, MA, USA); S. Buist (Oregon Health and Sciences University, Portland, OR, USA); W. Vollmer (Kaiser Permanente Center for Health Research, Portland, OR, USA); R. Roissin (University of Barcelona, Barcelona, Spain); J. Luna (University of Buenos Aires, Buenos Aires, Argentina); C. Lisboa (Catholic University of Chile, Santiago, Chile); C. Torres (Respiratory Colombian Society, Bogota, Colombia).

\section{REFERENCES}

1 Lopez AD, Mathers CD, Ezzati M, Jamison DT, Murray CJ. Global and regional burden of disease and risk factors, 2001: systematic analysis of population health data. Lancet 2006; 367: 1747-1757.

2 World Health Organization. Stop TB partnership. Tuberculosis in Countries. www.stoptb.org./countries/. Date last accessed: May 8, 2007.

3 Cowie RL, Mabena SK. Silicosis, chronic airflow limitation, and chronic bronchitis in South African gold miners. Am Rev Respir Dis 1991; 143: 80-84. 
4 Ehrlich RI, White N, Norman R, et al. Wheeze, asthma diagnosis and medication use: a national adult survey in a developing country. Thorax 2005; 60: 895-901.

5 Hnizdo E, Singh T, Churchyard G. Chronic pulmonary function impairment caused by initial and recurrent pulmonary tuberculosis following treatment. Thorax 2000; 55: 32-38.

6 Murray J, Kielkowski D, Reid P. Occupational disease trends in black South African gold miners. An autopsybased study. Am J Respir Crit Care Med 1996; 153: 706-710.

7 Lee JH, Chang JH. Lung function in patients with chronic airflow obstruction due to tuberculous destroyed lung. Respir Med 2003; 97: 1237-1242.

8 Leung CC, Chang KC, Law WS, et al. Determinants of spirometric abnormalities among silicotic patients in Hong Kong. Occup Med (Lond) 2005; 55: 490-493.

9 Mohan A, Premanand R, Reddy LN, et al. Clinical presentation and predictors of outcome in patients with severe acute exacerbation of chronic obstructive pulmonary disease requiring admission to intensive care unit. BMC Pulm Med 2006; 6: 27.

10 Jiménez $\mathrm{P}$, Torres V, Lehmann $\mathrm{F}$, et al. Chronic airways obstruction in patients with tuberculosis sequelae. A comparison with COPD. Rev Chil Enf Respir 2006; 22: 98-104.

11 Yaksic M, Tojo M, Cukier A, Stelmach R. Profile of a Brazilian population with severe chronic obstructive pulmonary disease. J Pneumol 2003; 29: 64-68.

12 Platino. Proyecto LatinoAmericano de Investigación en Obstrucción Pulmonar. www.platino-alat.org.

13 Menezes AM, Victora CG, Perez-Padilla R, the PLATINO Team. The Platino project: methodology of a multicenter prevalence survey of chronic obstructive pulmonary disease in major Latin American cities. BMC Med Res Methodol 2004; 4: 15.

14 Global strategy for the diagnosis, management and prevention of chronic obstructive pulmonary disease. Global Initiative for Chronic Obstructive Lung Disease, 2006. http:/ / goldcopd.org/Guidelineitem.asp?11=2\&12=1\&intId = 996. Date last accessed: July 30, 2007.

15 Pérez-Padilla R, Valdivia G, Muiño A, et al. [Spirometric reference values in 5 large Latin American cities for subjects aged 40 years or over.] Arch Bronconeumol 2006; 42: 317-325.

16 Menezes AM, Perez-Padilla R, Jardim JR, et al. Chronic obstructive pulmonary disease in five Latin American cities (the PLATINO study): a prevalence study. Lancet 2005; 366: 1875-1881.

17 Hallett WY, MartinC J. The diffuse obstructive pulmonary syndrome in a tuberculosis sanatorium. I. Etiologic factors. Ann Intern Med 1961; 54: 1146-1155.

18 Wright GW. Tuberculosis and pneumonia. In: Fenn WO, Rahn H, eds. Handbook of Physiology. Washington DC, American Physiological Society, 1965; pp. 1615-1622.

19 Birath G, Caro J, Malmberg R, Simonsson BG. Airways obstruction in pulmonary tuberculosis. Scand J Respir Dis 1966; 47: 27-36.

20 Lancaster JF, Tomashefski JF. Tuberculosis-a cause of emphysema. Am Rev Respir Dis 1963; 87: 435-437.

21 Snider GL, Doctor L, Demas TA, Shaw AR. Obstructive airway disease in patients with treated pulmonary tuberculosis. Am Rev Respir Dis 1971; 103: 625-640.

22 Elkington PT, Friedland JS. Matrix metalloproteinases in destructive pulmonary pathology. Thorax 2006; 61: 259-266.

23 Lowe CR. An association between smoking and respiratory tuberculosis. BMJ 1956; 2: 1081-1086.

24 McKenna MT, Hutton M, Cauthen G, Onorato IM. The association between occupation and tuberculosis. A population-based survey. Am J Respir Crit Care Med 1996; 154: 587-593.

25 Mishra VK, Retherford RD, Smith KR. Biomass cooking fuels and prevalence of tuberculosis in India. Int J Infect Dis 1999; 3: 119-129.

26 Pérez-Padilla R, Pérez-Guzmán C, Báez-Saldana R, TorresCruz A. Cooking with biomass stoves and tuberculosis: a case control study. Int J Tuberc Lung Dis 2001; 5: 441-447.

27 Davies PD, Yew WW, Ganguly D, et al. Smoking and tuberculosis: the epidemiological association and immunopathogenesis. Trans $R$ Soc Trop Med Hyg 2006; 100: 291-298.

28 United Nations. Millennium Campaign. About the Goals. Goal 6: Combat HIV / AIDS, malaria and other diseases. www. millenniumcampaign.org/site/pp.asp?c=grKVL2NLE\&b= 186386. Date last accessed: May 8, 2007. 